\title{
EFFECT OF INOCULUM LEVEL, TYPE, PLANT AGE AND ASSESSMENT DATE ON EVALUATING SUGAR BEET RESISTANCE METHODS FOR ROOT-KNOT NEMATODE, Meloidogyne incognita \\ Gohar, I. M. A. and M. F. Maareg \\ Department of Sugar Crops diseases \& Pests. Sugar Crops Research Institute, Agricultural Research Center, 12619, Giza, Egypt \\ Correspondent Author: Ibrahimgohar121@msn.com
}

\begin{abstract}
The objectives of this study were to determine the effect of inoculum level, inoculation date, assessment date and inoculum type, on evaluating $M$. incognita resistance in sugar beet, and to optimize the resistance screening technique used to categorize root-knot nematode resistant sugar beet cultivars under the greenhouse conditions $\left(25 \pm 2.5^{\circ} \mathrm{C}\right)$. A series of greenhouse tests were done using seven sugar beet varieties with three levels of resistance to $M$. incognita. The three resistance levels could be separated based on gall indices as early as two weeks after inoculation (WAI) using 6000 eggs of $M$. incognita per plant. Results indicated that based on gall index, low inoculum level (500 and 1000 eggs/ plant) could separate four sugar beet varieties from each other only on the fourth assessment date (8 WAI) for inoculum level 500 eggs/ plant and on the third assessment date (6 WAl) for 1000 eggs/ plant inoculum level. Harvest date affected galling in sugar beet roots $(P \leq$ $0.001)$; there was a significant interaction of harvest date $\times$ variety $(P \leq 0.001)$, the increase of gall index was greater for variety Elan than for the other tested verities.

Based on galled area index, the resistant and susceptible varieties could be separated successfully as early as 2 WAl. At the highest tested inoculation level (12000 eggs/ plant), but it couldn't be separate between the moderately resistant and the susceptible or between resistant and moderately resistant ones at $P \leq 0.001$. Based on eggs per gram root, the four sugar beet varieties with three levels of resistance to $M$. incognita were separated at the inoculation rate of 8000 eggs/ plant by $6 \mathrm{WAI}$ and at 500,1000,2000, 4000 and 12000 eggs/plant by 8 WAI. In addition to gall number, gall index, galled area index, eggs per gram root, egg mass number and egg mass index were also used to assess the resistance levels in the sugar beet varieties. Gall index was found to be the most sensitive method of all measures used for assessing resistance. Inoculum type i.e. eight thousand eggs and $2000 \mathrm{~J} 2$ did not result in significant differences in galled area index at the two investigated harvest dates. Plant age at time of inoculation affected gall development on the tested sugar beet varieties however; the effects on Av poly, Lados and M 9680 were not as great as on Del 939 and Elan. But, the same tested verities could not be separated into their appropriate resistance categories with inoculation at 0 and 40 day after planting.

The importance of such study is the identification of a rapid method for assessing resistance in sugar beet varieties to root-knot nematodes, takes less than 100 days.

Keywords: Egypt, evaluating, sugar beet, Meloidogyne incognita, greenhouse assessment date, varieties reaction, inoculation date, inoculum level, inoculum type, method, resistance evaluation, root-knot nematode, gall indices, eggmasses, varieties
\end{abstract}




\section{INTRODUCION}

It has been estimated that the average yield loss due to plant parasitic nematodes is around 12\% annually (Sasser and Freckman, 1987), reaching as high as $20 \%$ in certain crops (Koenning et al., 1999). Among the parasitic nematodes, root-knot nematodes which are the most important and wide spread where, every crop species grown is susceptible to one or more RKN species (Sasser, 1980). Meloidogyne spp. are obligate sedentary endoparasites and are known to occur across a broad range of climatic conditions. While Meloidogyne contains more than 70 described species, four species (M. incognita, $M$. arenaria, $M$. javanica and $M$. hapla) are responsible for $95 \%$ of infestations (Sasser et al., 1983). Owing to mentioned facts, sugar beet crop in Egypt faces great threat in its newly production areas, mainly from RKNs which were reported by Maareg et al. (1998) as the most prevailing nematode genera in Nubariya region. Management of root-knot nematode can include crop rotation, application of nematicides and use of resistant cultivars. Few profitable rotation crops are available because of the wide host range of RKNs. Use of nematicides is problematic because of the short-term efficacy (Dickson and Hewlett, 1989; Culbreath et al., 1992) and the cost to growers. There is a need for improved root-knot nematode management strategies, and the use of nematode-resistant sugar beet cultivars would be an effective and inexpensive approach to prevent yield and quality losses to RKNs. The existence of root-knot nematode resistance in rare strains of $B$. vulgaris ssp. Maritima was reported by Yu (1995). Breeding for resistance to root knot nematode in sugar beet has been a relatively recent endeavor (Weiland and $\mathrm{Yu}, 2003$ ).

In Egypt, numerous researchers reported that sugar beet crop is targeted by root knot nematodes, M. incognita and M. javanica (Ibrahim, 1982; Oteifa and El-Gindi, 1982; Abd-El-Massih et al., 1986; El-Eraki et al., 1986; Ismail et al., 1996; Maareg et al., 1998 and El- Nagdi et al., 2004). The majority of these studies were subjected to the effect of nematodes on the yield of sugar beet varieties and their susceptibility to nematodes (Ismail et al., 1996; Maareg et al., 1998 and El-Nagdi et al., 2004). Gohar and Maareg (2005) also, concluded that $M$. incognita larvae attack sugar beet plants resulting in decreasing in root and sugar yields, increased gradually to attain 51.3 and $68.4 \%$, respectively.

In the present study, seven sugar beet varieties were used as they were among several evaluated varieties by Sugar Crops Research Institute, Agriculture Research Center, Giza, Egypt. These varieties were along with other thirteen sugar beet varieties evaluated for Susceptibility to $M$. incognita by Maareg et al. (2005) and categorized according to their responses to $M$. incognita i.e. as resistant, moderately resistant and susceptible, etc. The present study may be contributes indirectly in the development of new sugar beet cultivars with resistance to RKNs, but, it suggested that it will create a reliable and efficient resistance screening procedure for accurate determination and segregation among sugar beet varieties reaction towards RKNs infection. This leads to boost control strategies for this pest. Thus, the 
objectives of this study were to: (1) determine the effects of inoculum level, inoculation date, assessment date and inoculum type, on evaluating $M$. incognita resistance in sugar beet, and (2) optimize the resistance screening technique used to categorize root-knot nematode resistant sugar beet cultivars under the greenhouse conditions.

\section{MATERIALS AND METHODS}

Sugar beet varieties: Seven sugar beet varieties with different levels of resistance to $M$. incognita were used in all experiments. The varieties included one resistant variety, Emma, three moderately resistant varieties, Av poly, Lados and M 9680 and three susceptible ones, Del 939, Elan and Helena. The origin, germ type and relative response of sugar beet used varieties to $M$. incognita are listed in Table (1).

Table (1): The origin, germ type and relative response to $M$. incognita

\begin{tabular}{|l|c|c|c|}
\hline Variety & Origin & Germ type & $\begin{array}{c}\text { R.R } \mathbf{R}^{\star} \text { To } \\
\text { M. } \text { incognita }\end{array}$ \\
\hline Av poly & Sweden & Mono & Moderately resistant \\
\hline Del 939 & Germany & Poly & Susceptible \\
\hline Elan & Sweden & Mono & Susceptible \\
\hline Helena & Netherlands & Mono & Susceptible \\
\hline Lados & Netherlands & Poly & Moderately resistant \\
\hline M 9680 & Denmark & Poly & Moderately resistant \\
\hline Emma & Sweden & Mono & Resistant \\
\hline
\end{tabular}

- $\quad{ }^{*}$ Relative response to $M$. incognita i.e. degree of sensitivity,

- Source: Maareg et al. (2005)

Nematode inocula: Meloidogyne incognita, originating from a sugar beet field in Nubariya region, was cultured alternately on tomato (Lycopersicon esculentum cv. Moneymaker) or eggplant (Solanum melongena cv. Blackbeauty) and sugar beet (beta vulgaris cv. Chems). Eggs for inoculum were extracted from tomato or eggplant roots by agitating in $0.05 \% \mathrm{NaOCl}$ (Sodium hypochlorite) for 2 to 3 min (Hussey and Barker, 1973). The eggs were then collected and rinsed with tap water on nested 150- and 25- $\mu \mathrm{m}$ pore sieves. To collect the second-stage juveniles (J2) for use as inoculum infected tomato or eggplant roots were placed in hatching dishes and incubated in a mist chamber. The J2 were then collected using 150- and 25$\mu \mathrm{m}$-pore sieves once a day for 3 to 5 days. During the collection period, J2 were stored in a $1-\mathrm{cm}$ aqueous suspension at $5^{\circ} \mathrm{C}$ prior to inoculation of sugar beet plants.

Resistance assessment: For all assessment methods, sugar beet plants were uprooted and washed clean of soil 2 to $10 \mathrm{wk}$ after inoculation (WAl). Criteria used to evaluate resistance levels in sugar beet were: gall number, gall index, galled area index, egg mass number, egg mass index and egg number per gram root. Gall index was on a scale of 0 to 5 adopted after (Taylor and Sasser, 1978), where $0=$ no galls; $1=1$ to $2 ; 2=3$ to $10 ; 3=11$ to $30 ; 4=31$ to 100 ; and $5=$ more than 100 galls. Galled area index was also 
on a scale of 0 to 5 , but it was based on the percentage of the root system with galls, took on (Hussey and Janssen, 2002), where $0=$ no galling; $1=$ trace infection with a few small galls; $2=25 \%$ roots galled; $3=26$ to $50 \% ; 4$ $=51$ to $75 \%$; and $5=>75 \%$ roots galled. For the assessments based on root galling, the numbers of galls were counted, and the root systems were rated using the two indices. The roots were then placed in beakers containing approximately $300 \mathrm{ml}$ of $0.05 \%$ phloxine B solution for 3 to $5 \mathrm{~min}$ to stain egg masses a bright red color so the number of egg masses per root system could be determined visually as accredited by (Holbrook et al., 1983). Egg mass index was on a scale of 0 to 5 as described for gall index. Fresh root systems were weighed and then agitated in $1 \% \mathrm{NaOCl}$ solution for $5 \mathrm{~min}$ to extract eggs. Eggs were collected on nested 150- and 25- $\mu \mathrm{m}$-pore sieves and counted. Egg number per gram root was then calculated and recorded.

Inoculum level and harvest date: The experiment was a $4 \times 8 \times 4$ factorial arrangement of treatments. There were four sugar beet varieties in these experiments, including Elan, Lados, Av poly and Emma. The seven inoculum levels were $0,500,1000,2000,4000,6000,8000$ and 12000 eggs/pot. The four assessment dates were 2, 4, 6 and 8 weeks after inoculation (WAI). A split- split plot treatment design was used with assessment dates as main plots, sub- plot contained inoculum level, i.e. inoculum level $\times$ assessment dates and sub-sub plots implied varieties, i.e. varieties $x$ inoculum level $\times$ assessment dates. All were randomized within six replicate in the main plots. Two seeds were planted in each $10 \times 10-\mathrm{cm} 2$ plastic pot filled with $800 \mathrm{~cm} 3$ steam-pasteurized $\left(132^{\circ} \mathrm{C}\right.$ for $6 \mathrm{hr}$ ) loamy sand (texture: $87 \%$ sand, $9 \%$ silt, $4 \%$ clay). After two weeks from emergence, plants were thinned to 1 seedling/pot. Week later, two holes about $5-\mathrm{cm}$ deep and $1-\mathrm{cm}$ wide were made in the soil around each 3-wk-old sugar beet seedling. A $2.5 \mathrm{ml}$ aliquot of inoculum suspension was applied to each with a pipette. Unless otherwise noted, the plants were maintained in a greenhouse at $25 \pm 2.5^{\circ} \mathrm{C}$ and watered as needed. At harvest dates 1 ( $2 \mathrm{WAI}$ ) and 2 (4 WAl), resistance was assessed by gall number, gall index and galled area index. At harvest date 3 (6 WAl), gall number, gall index, galled area index and egg number per gram root were evaluated. At harvest date 4 ( $8 \mathrm{WAl}$ ), two additional variables, egg mass number and egg mass index, were also assessed, but with experimental design adopted as split plot treatment with inoculum levels as main plots and sub-plots of varieties $x$ inoculum levels. The entire experiment was repeated.

Inoculum type: The experiment was a $4 \times 2 \times 2$ factorial arrangement of treatments. Four sugar beet varieties, Helena, M 9680, Lados and Emma, were evaluated at two inoculum levels and two harvest dates. The sugar beet varieties were grown and inoculated $2 \mathrm{wk}$ after planting with either $2000 \mathrm{~J} 2$ or 8000 eggs of $M$. incognita as previously described [The hatch rate of the eggs used in this test was $24.67 \%$ after 6 days ( $144 \mathrm{hr}$ ), thus inoculum levels of 8000 eggs and $2000 \mathrm{~J} 2$ were approximately equivalent]. A split- split plot treatment design was used with assessment dates as main plots, sub- plot contained inoculum type, i.e. inoculum type $\times$ assessment dates and sub-sub plots implied varieties, i.e. varieties $\times$ assessment date, varieties $\times$ inoculum type and varieties $\times$ inoculum type $\times$ assessment dates. All were randomized 
within six replicates in the main plots. Galled area index was used to evaluate the resistance level in the selected sugar beet varieties $2 \mathrm{WAI}$, whereas galled area index and egg number per gram root were used to evaluate resistance $10 \mathrm{WAl}$. But the later parameter viz egg number per gram root at 10 WAl was assessed through randomized complete blocks with six replicates in the main plots. The entire experiment was repeated one time under similar conditions.

Plant age effect: Six sugar beet varieties were evaluated: Del 939, Elan, Av poly, Lados, M 9680 and Emma. The varieties were planted in $20 \times 20-\mathrm{cm} 2$ plastic pots filled with $800 \mathrm{~cm} 3$ loamy sand/pot (texture: $87 \%$ sand, $9 \%$ silt, $4 \%$ clay) on five dates with 10-days intervals between dates. All plants were inoculated at the same date with 8000 eggs/pot. The ages of the sugar beet plants at the time of inoculation were 0 to $40 \mathrm{~d}$ after planting (DAP). The experimental design was a split- plot design, with plant age in the main plots and varieties in the sub-plot i.e. varieties $\times$ plant age (planting date).All randomized within six replicate main plots. Plants were harvested at 8 WAI. Galled area index and egg number per gram root were used to assess resistance. The experiment was repeated one time.

Statistical analysis: Data from the two trials of each experiment were combined for analysis of variance (ANOVA). Data were analyzed using MSTAT version 4 (1987), followed by testing significant differences among the means of different treatments by Duncan's Multiple Range Test at $p \leq$ 0.001 probability (this limitation is used for more accuracy) according to Duncan (1955). Unless otherwise stated. Any interaction effects that were not significant were removed, and the reduced model evaluated again. Main effects were considered significant when $P_{-} 0.05$ and adjusted with any significant interactions.

\section{RESULTS AND DISCUSSION}

Effect of inoculum level and harvest date: Galls on sugar beet plants were observed after two weeks from inoculation (2 WAl) and along with inoculum levels 500 up to 12000 eggs/ plant. Initial inoculum level of $M$. incognita affected gall number (Table, 2) and consequently gall index (Table, 3 ). Since, gall index was based on gall number i.e. it had the typical effect, thus the observations in this part of the presented result will coincide with the effect of the three studied factors i.e. inoculation level, assessment date and varieties and their interactions on gall index. For all four selected sugar beet varieties, gall index value increased as the inoculum level increased. However, the magnitude of the increase was not the same for all the varieties (inoculum $\times$ variety interaction, $P \leq 0.001$ ). From 500 up to 12000 eggs/ plant, the rate of increase in gall index was larger for the susceptible sugar beet variety Elan than for the moderately and resistant varieties. On Elan, 2000 eggs/ plant caused greater $(P \leq 0.001)$ gall index than 1000 eggs/plant did, while 8000 eggs/ plant were needed to cause gall index to be greater than that for 2,000 eggs/plant on moderately resistant varieties, Lados and Av poly $(P \leq 0.001)$. Whereas, the inoculum levels above 2000 eggs/ plant up to 12000 eggs/ 
plant raised gall index value slightly for Emma variety with no significant difference at $P \leq 0.001$. From Table, 2 also, it can be observed that inoculum level 1000 eggs/ plant didn't separate either between the susceptible variety Elan and the two other moderate resistant varieties (Lados and Av poly), neither between these moderate resistant varieties and the resistant variety Emma at $P \leq 0.001$, but, the above levels from 2000 to 12000 eggs/ plant, separated the four sugar beet varieties to their appropriate resistance categories.

Across the harvest dates, the four sugar beet varieties could be separated into the appropriate resistance categories using 2000, 4000, 6000, 8000 and 12000 eggs/ plant based on gall index. Low inoculum level (500 and 1000 eggs/ plant) could separate four sugar beet varieties from each other only on the fourth assessment date (8 WAl) for inoculum level 500 eggs/ plant and on the third assessment date (6 WAl) for 1000 eggs/ plant inoculum level.

Harvest date affected galling in sugar beet roots $(P \leq 0.001)$; however, there was a significant interaction of harvest date $\times$ variety $(P \leq$ 0.001 ) (Table, 2). From 2 to $8 \mathrm{WAI}$, the increase of gall index was greater for Elan than for the other three verities. The gall index did not differ at $P \leq 0.001$ between 4, 6 and $8 \mathrm{WAl}$ for the Elan, Lados and Av poly, whereas they did for them between the $2 \mathrm{WAl}$ and $8 \mathrm{WAl}$. But, the resistant varieties Emma had no significant difference in gall index values all over the four assessment dates at $P \leq 0.001$. Also, the increase in gall index value for the resistant variety, Emma was slight and steady and was much lower than for the moderately resistant and susceptible varieties.

Harvest date had significant effects on galling and egg production in sugar beet roots. Galls on roots were visible two weeks after inoculation, and gall index could be successfully used to separate the different resistance levels in the selected sugar beet varieties at that time. The different levels of resistance in this study were not correctly separated by eggs per gram root until eight weeks after inoculation with 8000 eggs/ plant. This is likely due to the high variability in egg numbers at the earlier harvest dates. Based on these observations, it can be concluded that $8 \mathrm{WAI}$ is necessary to detect differences in the ability of sugar beet to restrict nematode reproduction. Temperature has significant influences on penetration, development and reproduction of nematodes (Noe, 1991). Degree-days would have been more accurate than days after inoculation for determining resistance in plants, especially for early assessment dates. During these experiments, the temperature was around $25^{\circ} \mathrm{C}$ i.e. it was optimum temperature for nematode infection and development (Diez and Dusenbery, 1989).

The size of galls as well as the number of galls is related to the number of nematodes infecting roots, although the inoculum concentration may have less effect at later evaluation stages (Abdel-Momen et al., 1998; Vovlas et al., 2005). Results of the present work demonstrated that the later the harvest date, the lower was the inoculum level needed to separate the different levels of resistance. Based on gall index the initial inoculum level could be as low as 500 eggs/ plant to separate the three resistance levels at $8 \mathrm{WAl}$, or 8000 to $12000 \mathrm{eggs} /$ plant could be used to separate the varieties 
as early as 2 WAI. Therefore, if a rapid evaluation is required, higher inoculum levels can be used to achieve reliable results, and, if inoculum is a limiting factor, the screening period can be extended. However, to confirm the resistance by egg production level, over 6000 eggs/plant as initial inoculum and eight weeks from inoculation to harvest are still needed.

Data presented in (Table, 4) show that as inoculum level increased the galled area increased and among all the combinations of eight inoculum levels $\times$ four harvest dates, use of galled area index could separate only two resistance levels correctly in the far pairs i.e. between resistant and susceptible ones in 14 combinations. Based on galled area index, the resistant and susceptible varieties could be separated successfully as early as 2 WAl. At the highest tested inoculation level (12000 eggs/ plant), but it didn't separate between the moderately resistant and the susceptible or between resistant and moderately resistant ones at $P \leq 0.001$. At the final harvest date ( $8 \mathrm{WAI}$ ), could be separated at low inoculation level (500 eggs/ plant) the same aforementioned observations.

Table (2): Effect of inoculum level of Meloidogyne incognita and assessment date on gall number criterion for assessing resistance of four sugar beet varieties by combined analysis of two greenhouse trials $\left(25 \pm 2.5^{\circ} \mathrm{C}\right)$.

\begin{tabular}{|c|c|c|c|c|c|c|c|c|c|c|}
\hline \multirow{2}{*}{$\begin{array}{c}\text { Assessment } \\
\text { dates }\end{array}$} & \multirow{2}{*}{ Varieties } & \multicolumn{9}{|c|}{ Inoculum levels (eggs/plant) } \\
\hline & & 0 & 500 & 1000 & 2000 & 4000 & 6000 & 8000 & 12000 & Average \\
\hline \multirow{5}{*}{$\begin{array}{c}\text { Date } 1 \\
\text { (2 weeks) }\end{array}$} & Elan & 0.0 & 5.2 & 5.3 & 5.5 & 5.7 & 18.7 & 35.7 & 102.0 & 22.3 \\
\hline & Lados & 0.0 & 4.8 & 5.0 & 5.3 & 5.5 & 11.7 & 227 & 45.0 & 12.5 \\
\hline & Av poly & 0.0 & 5.0 & 5.2 & 5.3 & 5.5 & 11.7 & 23.7 & 47.5 & 13.0 \\
\hline & Emma & 0.0 & 4.7 & 4.9 & 5.0 & 5.3 & 5.6 & 7.6 & 10.0 & 5.4 \\
\hline & Average & 0.0 & 4.9 & 5.1 & 5.3 & 5.5 & 11.9 & 224 & 51.1 & 13.3 \\
\hline \multirow{5}{*}{$\begin{array}{c}\text { Date } 2 \\
\text { (4 weeks) }\end{array}$} & Elan & 0.0 & 5.5 & 5.5 & 5.5 & 5.7 & 29.8 & 101.0 & 179.5 & 41.6 \\
\hline & Lados & 0.0 & 5.3 & 5.5 & 5.5 & 5.7 & 21.8 & 54.7 & 71.3 & 21.2 \\
\hline & Av poly & 0.0 & 5.3 & 5.3 & 5.3 & 5.6 & 21.6 & 55.0 & 70.0 & 21.0 \\
\hline & Emma & 0.0 & 5.0 & 5.7 & 5.3 & 5.5 & 14.3 & 27.5 & 33.0 & 12.0 \\
\hline & Average & 0.0 & 5.3 & 5.5 & 5.4 & 5.6 & 21.9 & 59.6 & 82.5 & 24.0 \\
\hline \multirow{5}{*}{$\begin{array}{c}\text { Date } 3 \\
\text { (6 weeks) }\end{array}$} & Elan & 0.0 & 5.5 & 5.7 & 5.7 & 6.0 & 31.0 & 109.5 & 188.5 & 44.0 \\
\hline & Lados & 0.0 & 5.5 & 5.7 & 5.7 & 5.8 & 22.8 & 63.3 & 70.3 & 22.4 \\
\hline & Av poly & 0.0 & 5.3 & 5.6 & 5.6 & 5.8 & 22.4 & 63.5 & 74.5 & 22.8 \\
\hline & Emma & 0.0 & 5.3 & 5.5 & 5.5 & 5.7 & 15.5 & 30.0 & 33.0 & 12.6 \\
\hline & Average & 0.0 & 5.4 & 5.6 & 5.6 & 5.8 & 22.9 & 66.6 & 91.6 & 25.4 \\
\hline \multirow{5}{*}{$\begin{array}{c}\text { Date } 4 \\
\text { (8 weeks) }\end{array}$} & Elan & 0.0 & 6.0 & 6.5 & 6.5 & 7.3 & 100.0 & 159.5 & 199.5 & 60.7 \\
\hline & Lados & 0.0 & 5.8 & 6.3 & 6.5 & 6.8 & 29.2 & 66.3 & 77.7 & 24.8 \\
\hline & Av poly & 0.0 & 5.8 & 6.3 & 6.5 & 6.8 & 29.0 & 65.5 & 75.5 & 24.4 \\
\hline & Emma & 0.0 & 5.7 & 6.2 & 6.3 & 6.5 & 18.8 & 30.1 & 33.0 & 13.3 \\
\hline & Average & 0.0 & 5.8 & 6.3 & 6.5 & 6.9 & 44.3 & 80.4 & 96.4 & 30.8 \\
\hline \multirow{2}{*}{$\begin{array}{l}\text { Mean of } \\
\text { Varieties } \\
\text { Elan }\end{array}$} & & & & & & & & & & \\
\hline & & & & & & & & & & 42.1 \\
\hline \multirow{3}{*}{\begin{tabular}{|l} 
Lados \\
Av poly \\
Emma
\end{tabular}} & & & & & & & & & & 20.2 \\
\hline & & & & & & & & & & 20.3 \\
\hline & & & & & & & & & & 10.8 \\
\hline \multicolumn{2}{|c|}{ Mean of inoculum levels } & 0.0 & 5.4 & 5.6 & 5.7 & 6.0 & 23.8 & 57.2 & 81.9 & \\
\hline \multirow{2}{*}{$\begin{array}{l}\text { LS.D } \\
P \leq 0.001\end{array}$} & $\begin{array}{l}\text { Assessment } \\
\text { Dates }\end{array}$ & $\begin{array}{c}\text { Inoculum } \\
\text { levels }\end{array}$ & $\begin{array}{c}\text { Inoc. } L^{*} \\
X \\
\text { Ass. D. }\end{array}$ & Vars.*- & $\begin{array}{c}\text { Vars. } \\
\text { X. } \\
\text { Ass. D. }\end{array}$ & $\begin{array}{c}\text { Vars. } \\
\quad \times \\
\text { Inoc. L }\end{array}$ & \multicolumn{4}{|c|}{ Vars. X Inoc. L X Ass. D. } \\
\hline & 0.25 & 0.50 & 1.0 & 0.27 & 0.53 & 0.75 & \multicolumn{4}{|c|}{1.50} \\
\hline
\end{tabular}

Data presented are means of 12 replications (six replicates / trial) combined across harvest dates $(2,4,6$ and 8 weeks after inoculation).

* Inoc. L. = Inoculum level and Ass. D. = Assessment date. ** Vars. = Varieties 
Gohar, I. M. A. and M. F. Maareg

Table (3): Effect of inoculum level of Meloidogyne incognita and assessment date on gall index as resistance evaluating criterion for four sugar beet varieties by combined analysis of two greenhouse trials $\left(25 \pm 2.5^{\circ} \mathrm{C}\right)$.

\begin{tabular}{|c|c|c|c|c|c|c|c|c|c|c|}
\hline \multirow{2}{*}{$\begin{array}{l}\text { Assessment } \\
\text { dates }\end{array}$} & \multirow{2}{*}{ Varieties } & \multicolumn{9}{|c|}{ Inoculum levels (eggs/plant) } \\
\hline & & 0 & 500 & 1000 & 2000 & 4000 & 6000 & 8000 & 12000 & Average \\
\hline \multirow{5}{*}{$\begin{array}{c}\text { Date } 1 \\
\text { (2 weeks) }\end{array}$} & Elan & 0 & 2 & 2.2 & 2.5 & 2.8 & 3 & 4.8 & 5 & 2.8 \\
\hline & Lados & 0 & 1.8 & 2 & 2.2 & 2.5 & 3.1 & 3.2 & 3.3 & 2.3 \\
\hline & Av poly & 0 & 1.8 & 2 & 2.3 & 2.5 & 3.1 & 3.2 & 3.3 & 2.3 \\
\hline & Emma & 0 & 1.6 & 1.8 & 2 & 2.1 & 2.2 & 2.2 & 2.2 & 1.8 \\
\hline & Average & 0.0 & 1.8 & 2.0 & 2.3 & 2.5 & 2.9 & 3.4 & 3.5 & 2.3 \\
\hline \multirow{5}{*}{$\begin{array}{c}\text { Date } 2 \\
\text { (4 weeks) }\end{array}$} & Elan & 0 & 2.2 & 2.3 & 4.2 & 4.7 & 4.8 & 5 & 5 & 3.5 \\
\hline & Lados & 0 & 2 & 2.2 & 3 & 3.3 & 3.5 & 3.7 & 3.7 & 2.7 \\
\hline & Av poly & 0 & 2 & 2.2 & 3 & 3.3 & 3.5 & 3.7 & 3.7 & 2.7 \\
\hline & Emma & 0 & 1.8 & 2 & 2 & 2.3 & 2.3 & 2.5 & 2.5 & 1.9 \\
\hline & Average & 0.0 & 2.0 & 2.2 & 3.1 & 3.4 & 3.5 & 3.7 & 3.7 & 2.7 \\
\hline \multirow{5}{*}{$\begin{array}{l}\text { Date } 3 \text { (6 } \\
\text { weeks) }\end{array}$} & Elan & 0 & 2.3 & 4 & 4.5 & 4.7 & 4.8 & 5 & 5 & 3.8 \\
\hline & Lados & 0 & 2.2 & 2.7 & 3 & 3.2 & 3.5 & 3.5 & 3.7 & 2.7 \\
\hline & Av poly & 0 & 2.3 & 2.8 & 3 & 3.2 & 3.6 & 3.6 & 3.7 & 2.8 \\
\hline & Emma & 0 & 2 & 2.2 & 2.3 & 2.5 & 2.5 & 2.7 & 2.7 & 2.1 \\
\hline & Average & 0.0 & 2.2 & 2.9 & 3.2 & 3.4 & 3.6 & 3.7 & 3.8 & 2.9 \\
\hline \multirow{5}{*}{$\begin{array}{l}\text { Date } 4 \text { (8 } \\
\text { weeks) }\end{array}$} & Elan & 0 & 3.5 & 3.7 & 3.8 & 4.8 & 5 & 5 & 5 & 3.9 \\
\hline & Lados & 0 & 2.7 & 3 & 3.2 & 3.5 & 3.7 & 3.7 & 3.7 & 2.9 \\
\hline & Av poly & 0 & 2.8 & 3 & 3.2 & 3.5 & 3.5 & 3.7 & 3.7 & 2.9 \\
\hline & Emma & 0 & 2.2 & 2.3 & 2.5 & 2.5 & 2.7 & 2.7 & 2.7 & 2.2 \\
\hline & Average & 0.0 & 2.8 & 3.0 & 3.2 & 3.6 & 3.7 & 3.8 & 3.8 & 3.0 \\
\hline \multicolumn{11}{|l|}{$\begin{array}{l}\text { Mean of } \\
\text { Varieties }\end{array}$} \\
\hline Elan & & & & & & & & & & 3.5 \\
\hline Lados & & & & & & & & & & 2.7 \\
\hline Av poly & & & & & & & & & & 2.7 \\
\hline Emma & & & & & & & & & & 2.0 \\
\hline \multicolumn{2}{|c|}{ Mean of inoculum levels } & 0.0 & 2.2 & 2.5 & 2.9 & 3.2 & 2.5 & 3.6 & 3.7 & \\
\hline \multirow[t]{2}{*}{$\begin{array}{c}\text { L.S.D } \\
P \leq 0.001\end{array}$} & $\begin{array}{l}\text { Assessment } \\
\text { Dates }\end{array}$ & $\begin{array}{l}\text { Inoculum } \\
\text { levels }\end{array}$ & $\begin{array}{c}\text { Inoc. } \\
\mathrm{L}^{*} \\
\mathrm{X} \\
\text { Ass. } \\
\text { D. }\end{array}$ & Vars."* & $\begin{array}{c}\text { Vars. } \\
\text { X } \\
\text { Ass. } \\
\text { D. }\end{array}$ & $\begin{array}{c}\text { Vars. } \\
\text { X } \\
\text { Inoc. } \\
\text { L }\end{array}$ & \multicolumn{4}{|c|}{ Vars. X Inoc. L X Ass. D. } \\
\hline & 0.25 & 0.33 & 0.67 & 0.23 & 0.46 & 0.65 & \multicolumn{4}{|c|}{1.30} \\
\hline
\end{tabular}

Data presented are means of 12 replications (six replicates / trial) combined across harvest dates $(2,4,6$ and 8 weeks after inoculation).

* Inoc. L. = Inoculum level and Ass. D. = Assessment date.

** Vars. = Varieties.

Gall index was on a scale of 0 to 5 , where $0=$ no galls; $1=1$ to $2 ; 2=3$ to $10 ; 3=11$ to 30 ; $4=31$ to 100 ; and $5=$ more than 100 galls.

Data presented are means of 12 replications (six replicates / trial) combined across harvest dates (2, 4, 6 and 8 weeks after inoculation). ${ }^{*}$ Inoc. $\mathrm{L} .=$ Inoculum level and Ass. D. = Assessment date. ${ }^{* *}$ Vars. $=$ Varieties. Galled area index was on a scale of 0 to 5 , it was based on the percentage of the root system with galls, where $0=$ no galling; $1=$ trace infection with a few 
small galls; $2=25 \%$ roots galled; $3=26$ to $50 \% ; 4=51$ to $75 \%$; and $5=$ $>75 \%$ roots galled.

Table (4): Effect of inoculum level of Meloidogyne incognita and assessment date on galled area index criterion for assessing resistance of four sugar beet varieties by combined analysis of two greenhouse trials $\left(25 \pm 2.5^{\circ} \mathrm{C}\right)$.

\begin{tabular}{|c|c|c|c|c|c|c|c|c|c|c|}
\hline \multirow{2}{*}{$\begin{array}{l}\text { Assessment } \\
\text { dates }\end{array}$} & \multirow{2}{*}{ Varieties } & \multicolumn{9}{|c|}{ Inoculum levels (eggs/plant) } \\
\hline & & 0 & 500 & 1000 & 2000 & 4000 & 6000 & 8000 & 12000 & Average \\
\hline \multirow{5}{*}{$\begin{array}{l}\text { Date } 1 \\
\text { (2 weeks) }\end{array}$} & Elan & 0.00 & 0.83 & 1.00 & 1.17 & 1.83 & 2.17 & 3.50 & 4.33 & 1.85 \\
\hline & Lados & 0.00 & 0.21 & 0.63 & 0.67 & 0.83 & 1.00 & 1.75 & 2.17 & 0.91 \\
\hline & Av poly & 0.00 & 0.29 & 0.79 & 1.00 & 1.00 & 0.88 & 1.83 & 2.00 & 0.97 \\
\hline & Emma & 0.00 & 0.00 & 0.00 & 0.42 & 0.46 & 0.42 & 0.46 & 0.63 & 0.30 \\
\hline & Average & 0.0 & 0.3 & 0.6 & 0.8 & 1.0 & 1.1 & 1.9 & 2.3 & 1.0 \\
\hline \multirow{5}{*}{$\begin{array}{c}\text { Date } 2 \\
\text { (4 weeks) }\end{array}$} & Elan & 0.00 & 1.83 & 2.33 & 2.50 & 3.00 & 3.50 & 3.83 & 3.91 & 2.61 \\
\hline & Lados & 0.00 & 0.29 & 0.58 & 0.88 & 1.75 & 1.83 & 1.92 & 2.42 & 1.21 \\
\hline & Av poly & 0.00 & 0.67 & 0.83 & 1.17 & 1.83 & 2.00 & 2.17 & 2.33 & 1.38 \\
\hline & Emma & 0.00 & 0.21 & 0.25 & 0.46 & 0.50 & 0.63 & 1.17 & 1.25 & 0.56 \\
\hline & Average & 0.0 & 0.8 & 1.0 & 1.3 & 1.8 & 2.0 & 2.3 & 2.5 & 1.4 \\
\hline \multirow{5}{*}{$\begin{array}{l}\text { Date } 3 \\
\text { weeks) }\end{array}$} & Elan & 0.00 & 2.21 & 2.50 & 3.33 & 3.67 & 3.75 & 3.88 & 4.08 & 2.93 \\
\hline & Lados & 0.00 & 0.92 & 1.17 & 1.42 & 1.83 & 2.00 & 2.21 & 3.33 & 1.61 \\
\hline & Av poly & 0.00 & 0.83 & 1.00 & 1.33 & 1.92 & 2.17 & 2.28 & 3.28 & 1.60 \\
\hline & Emma & 0.00 & 0.33 & 0.42 & 0.46 & 0.63 & 0.75 & 1.17 & 1.46 & 0.65 \\
\hline & Average & 0.0 & 1.1 & 1.3 & 1.6 & 2.0 & 2.2 & 2.4 & 3.0 & 1.7 \\
\hline \multirow{5}{*}{$\begin{array}{l}\text { Date } 4 \text { (8 } \\
\text { weeks) }\end{array}$} & Elan & 0.00 & 3.33 & 3.58 & 3.88 & 4.21 & 4.67 & 4.83 & 4.98 & 3.69 \\
\hline & Lados & 0.00 & 1.42 & 1.83 & 1.92 & 1.98 & 2.21 & 2.75 & 3.21 & 1.92 \\
\hline & Av poly & 0.00 & 1.33 & 1.75 & 2.00 & 213 & 2.43 & 2.83 & 3.17 & 1.96 \\
\hline & Emma & 0.00 & 0.42 & 0.67 & 0.83 & 0.92 & 1.21 & 1.42 & 1.67 & 0.89 \\
\hline & Average & 0.00 & 1.6 & 2.0 & 2.2 & 2.3 & 2.6 & 3.0 & 3.3 & 2.11 \\
\hline \multicolumn{11}{|l|}{$\begin{array}{l}\text { Mean of } \\
\text { Varieties }\end{array}$} \\
\hline Elan & & & & & & & & & & 2.8 \\
\hline Lados & & & & & & & & & & 1.4 \\
\hline Av poly & & & & & & & & & & 1.5 \\
\hline Emma & & & & & & & & & & 0.6 \\
\hline \multicolumn{2}{|c|}{ Mean of inoculum levels } & 0.0 & 0.9 & 1.2 & 1.5 & 1.8 & 2.0 & 2.4 & 2.8 & \\
\hline \multirow[t]{2}{*}{$\begin{array}{c}\text { L.S.D } \\
P \leq 0.001\end{array}$} & $\begin{array}{l}\text { Assessment } \\
\text { Dates }\end{array}$ & $\begin{array}{c}\text { Inoculum } \\
\text { levels }\end{array}$ & $\begin{array}{c}\text { Inoc. } \\
\mathrm{L}^{*} \\
\mathrm{X} \\
\text { Ass. } \\
\text { D. }\end{array}$ & Vars."* & $\begin{array}{c}\text { Vars. } \\
\text { X } \\
\text { Ass. } \\
\text { D. }\end{array}$ & $\begin{array}{c}\text { Vars. } \\
\mathrm{X} \\
\text { Inoc. } \\
\mathrm{L}\end{array}$ & \multicolumn{4}{|c|}{ Vars. X Inoc. L X Ass. D. } \\
\hline & 0.77 & 1.07 & 2.13 & 0.76 & 0.70 & 214 & \multicolumn{4}{|c|}{4.28} \\
\hline
\end{tabular}

In regard to the effect of inoculum level the results of present study coincide with El-Sherif et al. (2007) who revealed that in two pot experiments that were separately conducted to determine the influence of four or three inoculum levels $(0,250,500$ and 1000 or 0,1000 and 2000 nematode eggs/ $850 \mathrm{~g} \mathrm{soil} / \mathrm{pot}$ ) of Meloidogyne incognita on population density of the nematode and host reaction of two solanacious plants under partly controlled greenhouse. Nematode reproduction and host damage were both affected by 
the initial inoculum levels and revealed more responses as the inoculum level increased from 250 to 1000 eggs/ plant. The rate of build up of $M$. incognita on plants increased when the initial inoculum (Pi) level was increased up to 2000 eggs per pepper plant. Galls and egg masses/root system increased as Pi was increased on both host plants i.e. tomato or pepper.

Based on eggs per gram root, Table, 5 indicates that the four sugar beet varieties with three levels of resistance to $M$. incognita were separated at the inoculation rate of 8000 eggs/ plant by $6 \mathrm{WAl}$ and at 500,1000, 2000, 4000 and 12000 eggs/plant by $8 \mathrm{WAI}$ (Table 5). At low inoculation levels (500 to 6000 plus level 12000 eggs/ plant) at early harvest date (6 WAl), the four varieties were not separated into their appropriate resistance classification due to the high variability of eggs per gram root.

Table (5): Effect of inoculum level of Meloidogyne incognita and assessment date on eggs number/ $\mathrm{g}$ root as a criterion for evaluating resistance of four sugar beet varieties by combined analysis of two greenhouse trials $\left(25 \pm 2.5^{\circ} \mathrm{C}\right)$.

\begin{tabular}{|c|c|c|c|c|c|c|c|c|c|c|}
\hline \multirow{2}{*}{$\begin{array}{l}\text { Assessment } \\
\text { dates }\end{array}$} & \multirow[b]{2}{*}{ Varieties } & \multicolumn{9}{|c|}{ Inoculum levels (eggs/plant) } \\
\hline & & 0 & 500 & 1000 & 2000 & 4000 & 6000 & 8000 & 12000 & Average \\
\hline \multirow{5}{*}{$\begin{array}{c}\text { After } \\
6 \text { weeks }\end{array}$} & Elan & 0.0 & 267.0 & 387.0 & 589.0 & 715.0 & 1213.0 & 2217.0 & 3376.0 & 1095.5 \\
\hline & Lados & 0.0 & 67.0 & 111.0 & 211.0 & 304.0 & 378.0 & 563.0 & 712.0 & 293.3 \\
\hline & Av poly & 0.0 & 53.0 & 83.0 & 103.0 & 169.0 & 219.0 & 412.0 & 523.0 & 195.3 \\
\hline & Emma & 0.0 & 5.0 & 7.0 & 9.0 & 13.0 & 19.0 & 27.0 & 33.0 & 14.1 \\
\hline & Average & 0.0 & 98.0 & 147.0 & 228.0 & 300.3 & 457.3 & 804.8 & 1161.0 & 399.5 \\
\hline \multirow{5}{*}{$\begin{array}{c}\text { After } \\
8 \text { weeks }\end{array}$} & Elan & 0.0 & 3356.0 & 3711.0 & 6251.0 & 7222.0 & 8889.0 & 9654.0 & 10111.0 & 6149.3 \\
\hline & Lados & 0.0 & 707.0 & 1011.0 & 1523.0 & 1893.0 & 2546.0 & 3125.0 & 3687.0 & 1811.5 \\
\hline & Av poly & 0.0 & 654.0 & 1123.0 & 1452.0 & 1799.0 & 2358.0 & 3547.0 & 3754.0 & 1835.9 \\
\hline & Emma & 0.0 & 41.0 & 53.0 & 57.0 & 57.0 & 73.0 & 83.0 & 101.0 & 58.1 \\
\hline & Average & 0.0 & 1189.5 & 1474.5 & 2320.8 & 2742.8 & 3466.5 & 41023 & 4413.3 & 2463.7 \\
\hline \multirow{2}{*}{$\begin{array}{l}\text { Mean of } \\
\text { Varieties } \\
\text { Elan }\end{array}$} & & & & & & & & & & \\
\hline & & & & & & & & & & 3622.4 \\
\hline Lados & & & & & & & & & & 1052.4 \\
\hline \multicolumn{2}{|l|}{ Av poly } & & & & & & & & & 1015.6 \\
\hline \multicolumn{2}{|c|}{\begin{tabular}{|l|l} 
Emma & \\
\end{tabular}} & & & & & & & & & 36.1 \\
\hline \multicolumn{2}{|c|}{ Mean of inoculum levels } & 0.0 & 643.8 & 1678.0 & 1274.4 & 1521.5 & 1961.9 & 2453.5 & 2787.1 & \\
\hline \multirow[t]{2}{*}{$\begin{array}{c}\text { LS.D } \\
P \leq 0.001\end{array}$} & $\begin{array}{l}\text { Assessment } \\
\text { Dates }\end{array}$ & $\begin{array}{l}\text { Inoculum } \\
\text { levels }\end{array}$ & $\begin{array}{c}\text { Inoc. } \\
\mathrm{L}^{*} \\
\text { X } \\
\text { Ass. } \\
\text { D. } \\
\end{array}$ & Vars.** & $\begin{array}{c}\text { Vars. } \\
\text { X } \\
\text { Ass. } \\
\text { D. }\end{array}$ & $\begin{array}{c}\text { Vars. } \\
\text { X } \\
\text { Inoc. } \\
\text { L }\end{array}$ & \multicolumn{4}{|c|}{ Vars. X Inoc. L X Ass. D. } \\
\hline & 2.72 & 11.30 & 33.67 & 4.75 & 11.02 & 143.54 & \multicolumn{4}{|c|}{1147.15} \\
\hline
\end{tabular}

Data presented are means of 12 replications (six replicates / trial) combined across harvest dates (6 and 8 weeks after inoculation). * Inoc. L. = Inoculum level and Ass. D. $=$ Assessment date.

** Vars. = Varieties

In addition to gall number, gall index, galled area index, eggs per gram root, egg mass number and egg mass index were also used to assess the resistance levels in the sugar beet varieties. The ability of these assessment methods to precisely separate the different levels of resistance is digested and summarized in Table, 6 . Gall number could separate the four varieties correctly by 2, 4, 6 and $8 \mathrm{WAI}$ at only the high inoculum levels (6000 
up to 12000 eggs/ plant), whereas, at 6000,8000 and 12000 eggs/ plant by 2 WAI, also at 6000 and 8000 by 4, 6 and WAl. Eggmass number was not good measure to separate the four varieties in this study from the first inoculum level of 500 eggs/ plant up to the highest one (12000 eggs/ plant), and the same for eggmass index was not adequate to segregate between resistance levels with inoculum levels at 8 WAl due to the equal values of eggmasses index achieved for the most tested varieties with no segregation among them except for the resistant one. Generally, the higher the inoculum level used, the less time was needed to separate the varieties correctly based on gall number or gall index. Both gall index and galled area index were positively correlated $(P<0.001)$ with eggs per gram root $(r=0.7154$ and 0.7336 , respectively); however, gall index was the most sensitive method of all measures used for assessing resistance. It provided more choices on combinations of inoculum level $\times$ harvest date to separate the four sugar beet varieties successfully than galled area index, eggmasses or/and eggmasses index.

In plant nematology, resistance is used to describe the ability of a plant to suppress development or reproduction of the nematode (Roberts, 2002). For root knot nematodes, the symptoms can be evaluated with as sufficient ease, accuracy and precision as for some fungal diseases, such as leaf spot and rust. Therefore, the term resistance is also used to describe the capacity of a host to suppress the disease (Sasser et al., 1984; Roberts, 2002) as in general plant pathology. Sugar beet breeders, geneticists and nematologists have evaluated sugar beet genotypes for root-knot nematode resistance based on indices of root galling and/or egg mass production (YU, 1995 and 2003; Yu et al., 2001) or egg counts (Abdel-Momen et al., 1998; Choi et al., 1999). Others also have used gall counts to evaluate resistance to root-knot nematodes in plants (Harris et al., 2003). Gall number and the degree of galling may be used to reflect the ability of a plant to diminish or conquer the attack by the root-knot nematode. However, they do not indicate nematode reproduction directly, while eggmass number, egg mass index and egg number per gram root do.

The use of eggs per gram root also separated the three resistance levels correctly in more combinations of inoculum level $\times$ harvest date than the use of egg masses. Therefore, we agree with Luzzi et al. (1987) that, for advanced breeding lines, the quantitative data on egg numbers will give a better indication of root-knot nematode resistance than eggmass numbers. In comparison with galled area index (based on percentage of infested root) and gall number or gall index (based on gall number), was more robust, in that it separated the sugar beet varieties into their appropriate resistance categories. Additionally, it was time-consuming and difficult to assess the galled area percentage in sugar beet at later harvest dates, since galled area are usually diffused distinctly in different parts of the infested sugar beet root. Therefore, the consideration in this study is suggested to be due to gall index as a better indicator of the resistance level than galled area index and eggmasses number or index. 
Table (6): Summary of the evaluation results under eight inoculum levels of Meloidogyne incognita at four harvest dates by six assessment criteria when tested in two greenhouse trials $\left(25 \pm 2.5^{\circ} \mathrm{C}\right)$.

\begin{tabular}{|c|c|c|c|c|c|c|c|c|c|}
\hline \multirow{2}{*}{ criterion } & \multirow{2}{*}{$\begin{array}{l}\text { Harvest } \\
\text { Date }\end{array}$} & \multicolumn{8}{|c|}{ Inoculum level (eggs/plant) } \\
\hline & & 0 & 500 & 1000 & 2000 & 4000 & 6000 & 8000 & 12000 \\
\hline \multirow{4}{*}{$\begin{array}{c}\text { Gall } \\
\text { number }\end{array}$} & 2 WAI & $\mathrm{N}$ & $\mathbf{N}$ & $\mathbf{N}$ & $\mathbf{N}$ & $\mathrm{N}$ & $\bar{Y}$ & $\mathbf{Y}$ & $\mathbf{Y}$ \\
\hline & 4WAI & $\mathrm{N}$ & $\mathrm{N}$ & $\mathrm{N}$ & $\mathbb{N}$ & $\mathbf{N}$ & Y & Y & $\mathrm{N}$ \\
\hline & 6 WAI & $\mathrm{N}$ & $\mathrm{N}$ & $\mathbf{N}$ & $\bar{N}$ & $\mathrm{~N}$ & $\mathbf{Y}$ & $\mathbf{Y}$ & $\mathrm{N}$ \\
\hline & 8 WAI & $\bar{N}$ & $\bar{N}$ & $\mathbf{N}$ & $\overline{\mathrm{N}}$ & $\mathrm{N}$ & $\mathbf{Y}$ & $\mathbf{Y}$ & $\mathbf{N}$ \\
\hline \multirow{4}{*}{$\begin{array}{c}\text { Gall } \\
\text { index }\end{array}$} & 2 WAI & $\mathrm{N}$ & $\mathrm{N}$ & $\mathrm{N}$ & $\bar{N}$ & $\mathrm{~N}$ & $\mathrm{~N}$ & $\bar{Y}$ & $\mathbf{Y}$ \\
\hline & 4 WAI & $\mathrm{N}$ & $\mathrm{N}$ & $\mathrm{N}$ & $\bar{Y}$ & $\mathbf{Y}$ & $\mathrm{Y}$ & $\bar{Y}$ & $\bar{Y}$ \\
\hline & 6 WAl & $\mathrm{N}$ & $\mathrm{N}$ & $\mathrm{Y}$ & $\mathrm{Y}$ & $\mathrm{Y}$ & $\mathbf{Y}$ & $\mathrm{Y}$ & $\mathrm{Y}$ \\
\hline & 8 WAI & $\mathrm{N}$ & $\mathrm{N}$ & $\dot{Y}$ & $\mathrm{~N}$ & $\bar{Y}$ & $\bar{Y}$ & $\bar{Y}$ & $\bar{Y}$ \\
\hline \multirow{4}{*}{$\begin{array}{c}\text { Galled } \\
\text { area } \\
\text { index }\end{array}$} & 2 WAI & $\mathrm{N}$ & $\mathrm{N}$ & $\mathrm{N}$ & $\mathrm{N}$ & $\mathbf{N}$ & $\mathrm{N}$ & $\mathbf{N}$ & $\mathbf{N}$ \\
\hline & 4 WAI & $\mathrm{N}$ & $\mathrm{N}$ & $\mathrm{N}$ & $\mathrm{N}$ & $\mathrm{N}$ & $\mathrm{N}$ & $\mathbf{N}$ & $\mathbf{N}$ \\
\hline & 6 WAI & $\mathrm{N}$ & $\mathrm{N}$ & $\mathbf{N}$ & $\mathrm{N}$ & $\mathrm{N}$ & $\mathrm{N}$ & $\mathbf{N}$ & $\mathrm{N}$ \\
\hline & 8 WAI & $\mathrm{N}$ & $\mathrm{N}$ & $\mathrm{N}$ & $\mathrm{N}$ & $\mathrm{N}$ & $\mathrm{N}$ & $\mathbf{N}$ & $\mathrm{N}$ \\
\hline \multirow{2}{*}{$\begin{array}{c}\text { Eggs/ g } \\
\text { root }\end{array}$} & 6 WAI & $\mathrm{N}$ & $\mathbf{N}$ & $\mathbf{N}$ & $\mathrm{N}$ & $\mathrm{Y}$ & $\mathrm{N}$ & $\mathbf{N}$ & $\mathbf{N}$ \\
\hline & $8 \mathrm{WAI}$ & $\mathrm{N}$ & $\mathrm{Y}$ & $\mathrm{Y}$ & $\mathrm{Y}$ & $\mathrm{N}$ & $\mathrm{N}$ & $\mathbf{N}$ & $\mathrm{Y}$ \\
\hline $\begin{array}{c}\text { Eggmass } \\
\text { number }\end{array}$ & 8 WAI & $\mathrm{N}$ & $\mathrm{N}$ & $\mathbf{N}$ & $\mathbf{N}$ & $\mathrm{N}$ & $\mathrm{N}$ & $\mathbf{N}$ & $\mathbf{N}$ \\
\hline $\begin{array}{c}\text { Eggmass } \\
\text { index }\end{array}$ & 8 WAI & $\mathrm{N}$ & $\mathrm{N}$ & $\mathbf{N}$ & $\mathbf{N}$ & $\mathrm{N}$ & $\mathrm{N}$ & $\mathbf{N}$ & $\mathbf{N}$ \\
\hline
\end{tabular}

Y: The four sugar beet varieties Elan (susceptible to $M$. incognita), Lados, Av poly (moderately resistant to $M$. incognita), and Emma (resistant to $M$. Incognita) were separated in their appropriate resistance categories in the combination of inoculum level x harvest date;

$\mathrm{N}$ : The four varieties were not separated in their appropriate resistance categories in the combination of inoculum level $\times$ harvest date.

Gall index: $0=$ no galls; $1=1-2 ; 2=3-10 ; 3=11-30 ; 4=31-100 ;$ and $5=$ more than 100 galls.

Galled area index: $0=$ no galls, $1=$ trace infection with a few small galls, $2=25 \%$ root galled, $3=26-50 \%, 4=51-75 \%$, and $5=>75 \%$ of root galled.

Mass index: $0=$ no egg masses; $1=1-2 ; 2=3-10 ; 3=11-30 ; 4=31-100 ;$ and $5=$ more than 100 egg masses.

Inoculum type: The inoculum levels of 8000 eggs and $2000 \mathrm{~J} 2$ were approximately equivalent in their potentiality as previously described in the materials and methods. Eight thousand eggs and $2000 \mathrm{~J} 2$ did not result in significant differences in galled area index at the two harvest dates (Table, 7). The resistance classification was also similar between the two inoculum types. The three resistance levels in the four varieties were distinguished according to their true categories from each other by $2000 \mathrm{~J} 2$ and 8000 eggs at 2 and $10 \mathrm{WAI}$, based on galled area index or eggs per gram root. The effect of inoculum type on eggs number/ $\mathrm{g}$ root was tested at one date only (after $10 \mathrm{WAI}$ ), and it had the same trend of galled area index in regard to its ability to discriminate the four sugar beet varieties to their categories, although there was a significant difference between the resulted eggs/ $\mathrm{g}$ root for each inoculum type (Figure, 1). 
Table (7): Effect of Inoculum type on gall area index and eggs number/ $\mathrm{g}$ root for four sugar beet varieties inoculated with two type of $M$. incognita inoculum at two different assessment dates

\begin{tabular}{|c|c|c|c|c|c|c|}
\hline \multirow{3}{*}{ Varieties } & \multirow{2}{*}{\multicolumn{2}{|c|}{$\begin{array}{l}\text { 2 WAI } \\
\text { Gall area index }\end{array}$}} & \multirow{2}{*}{\multicolumn{2}{|c|}{$\begin{array}{c}10 \text { WAI } \\
\text { Gall area index }\end{array}$}} & \multirow{2}{*}{\multicolumn{2}{|c|}{$\begin{array}{c}\text { 10 WAl } \\
\text { Eggs/ g root }\end{array}$}} \\
\hline & & & & & & \\
\hline & $\begin{array}{c}2000 \\
\mathrm{j} 2\end{array}$ & $\frac{8000}{E}$ & $\begin{array}{l}2000 \\
j 2\end{array}$ & $\begin{array}{l}8000 \\
E\end{array}$ & $\begin{array}{l}2000 \\
\mathrm{j} 2\end{array}$ & $8000 \mathrm{E}$ \\
\hline Helena & 3.56 & 3.5 & 4.37 & 4.42 & 3312 & 4425 \\
\hline M 9680 & 242 & 2.34 & 3.42 & 3.38 & 299 & 1859 \\
\hline Lados & 237 & 2.49 & 2.42 & 2.38 & 311 & 1699 \\
\hline Emma & 0.17 & 0.21 & 0.67 & 0.75 & 51 & 55 \\
\hline CV\% & 7.51 & 7.49 & 6.65 & 6.51 & 0.35 & 0.24 \\
\hline \multicolumn{7}{|l|}{ Mean of Varieties } \\
\hline Elan & & & & 3.96 & & 3868.50 \\
\hline Lados & & & & 2.89 & & 1079.00 \\
\hline Av poly & & & & 2.67 & & 1005.00 \\
\hline Emma & & & & 0.45 & & 53.00 \\
\hline Mean of inoculum levels & 213 & 2.14 & 2.71 & 2.83 & 993.3 & 2009.5 \\
\hline \multirow[t]{2}{*}{$\begin{array}{c}\text { L.S.D } \\
P \leq 0.001\end{array}$} & Vars. & $\begin{array}{l}\text { Inoc. } \\
\text { Type }\end{array}$ & $\begin{array}{l}\text { Ass. } \\
\text { Date }\end{array}$ & $\begin{array}{c}\text { Vars } \\
\mathbf{X} \\
\text { Inoc. } \\
\text { Type }\end{array}$ & $\begin{array}{c}\text { Vars. } \\
\text { X } \\
\text { Ass. } \\
\text { Date. }\end{array}$ & $\begin{array}{c}\text { Inoc. } \\
\text { Type } \\
\text { X } \\
\text { Ass. } \\
\text { Date }\end{array}$ \\
\hline & 0.11 & 0.08 & 0.08 & 0.15 & 0.15 & 0.11 \\
\hline $\begin{array}{l}\text { Vars. XInoc. Type X } \\
\text { Ass.Date }\end{array}$ & \multicolumn{6}{|c|}{0.22} \\
\hline
\end{tabular}

Galled area index: $0=$ no galls, $1=$ trace infection with a few small galls, $2=25 \%$ root galled, $3=2650 \%, 4=51-75 \%$, and $5=>75 \%$ of root galled.

Data presented are means of 12 replications (six replications/ trial).

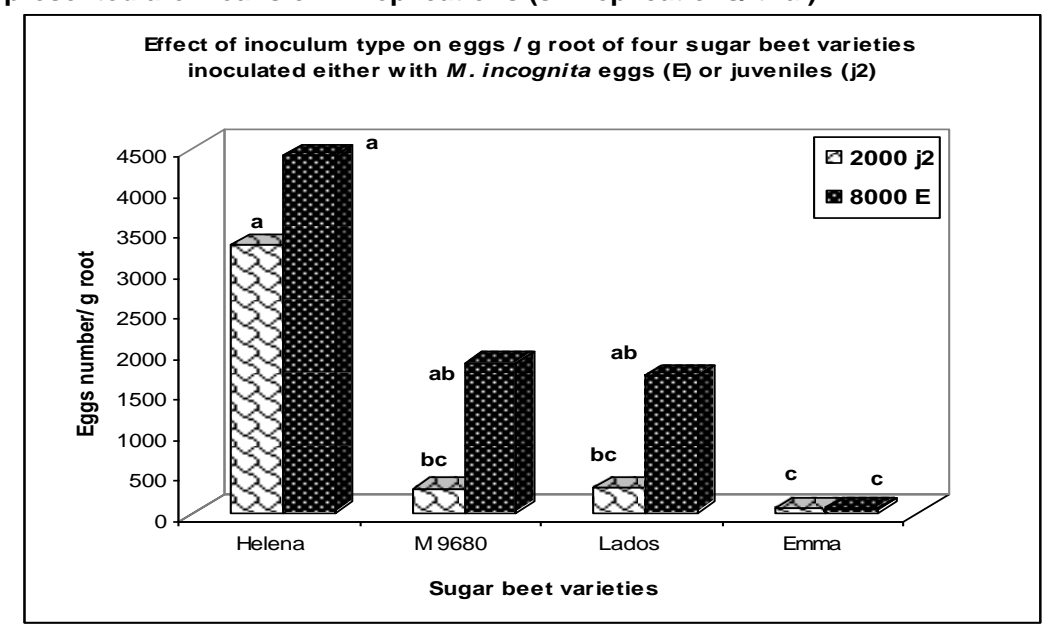

Figure 1: Effect of inoculum type eggs number/ $g$ root (egg production) in different sugar beet varieties Bars within a genotype with the same letter are not significantly different $(P \leq 0.001)$. 
Also, from Table, 7 , the coefficients of variation (CV) of galled area index for $2000 \mathrm{~J} 2$ and 8000 eggs were similar at both 2 and $10 \mathrm{WAl}$. So, the situation with the $\mathrm{CV}$ for eggs per gram root for $2000 \mathrm{~J} 2$ was $0.35 \%$ and 0.24 $\%$ for 8000 eggs (both $<1.0$ ) at $10 \mathrm{WAI}$, which suggested that the inoculum of 2000 juveniles had the same variability of 8000 eggs.

$\mathrm{J} 2$, intact eggmasses or egg suspensions can be used as inoculum for resistance screening tests (Hussey and Janssen, 2002). Intact egg masses are typically not used for inoculum because they are difficult to collect, quantify and disperse in the soil. Only J2 and egg suspensions were compared in these experiments, and both produced similar results as previously mentioned. No significant differences in gall index and nematode reproduction were found at 2 and $10 \mathrm{WAl}$ assessments using either type of inoculum. Compared with egg inoculum, no advantages were seen with J2 inoculum.

Plant age at inoculation: Among the six sugar beet tested varieties, Del 939 and Elan were susceptible, Av poly, Lados and M 9680 were moderately resistant and Emma was resistant. Plant age at time of inoculation affected gall development on the six varieties (Figure, 2); however, the effects on Av poly, Lados and M 9680 were not as great as on Del 939 and Elan. Inoculation on 10 days after planting (DAP) resulted in the highest gall index on all used varieties except for Lados, which had greatest galling when inoculated on 20 DAP. Inoculation on 40 DAP didn't separate the six varieties in their correct resistance categorization due to the reduced gall indices of the susceptible varieties, Del 939 and Elan.

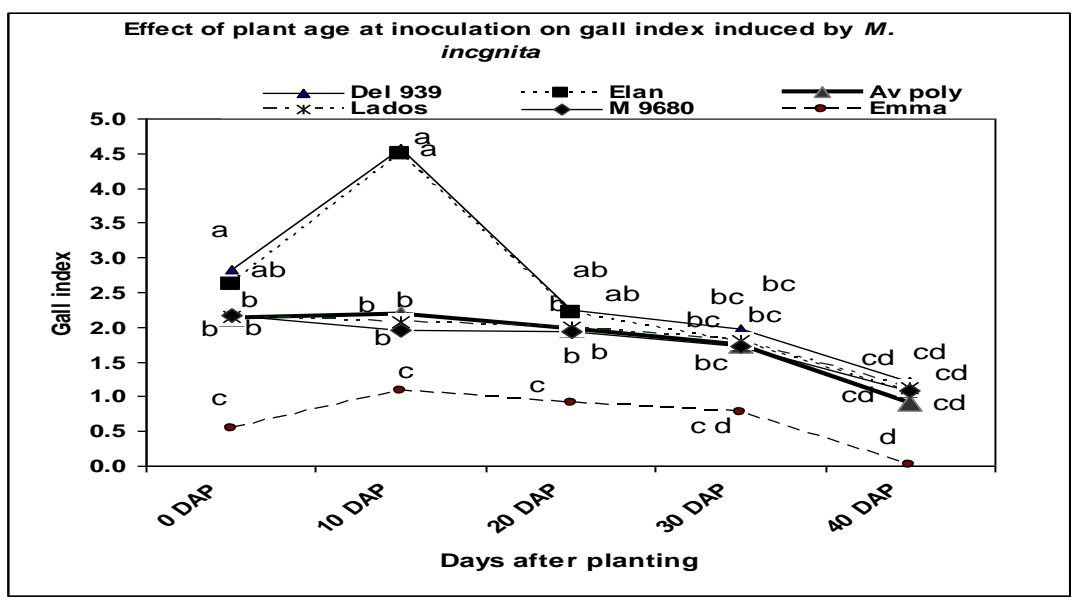

Figure 2: Root galling on six sugar beet varieties inoculated with Meloidogyne incognita at different days after planting (DAP). Gall index 2: $0=$ no galling, $1=$ trace infection with a few small galls, $2=\_25 \%$ roots galled, $3=25-50 \%, 4=51-75 \%$ and $5=\_75 \%$ of root galled. For each varieties, galled area index at each date interval that differ $\quad(P \leq 0.001)$ according to Duncan least significant difference (LSD) test are indicated by different letters around the symbols. 
In this experiment, the variety, DAP and variety $\times$ DAP had effect on nematode reproduction (Table 8$)$ and were significant $(P \leq .001)$. The eggs per gram root for all the varieties decreased on inoculation 40 DAP. In contrast, inoculation at 10,20 and 30 DAP resulted in lower $(P \leq 0.001)$ reproduction on the resistant varieties Emma than on the susceptible varieties Del 939 and Elan. However, such differences between susceptible and moderately resistant varieties were not always noticeable (Table 8 ). The six sugar beet varieties could not be separated into their appropriate resistance categories with inoculation at 0 and 40 DAP. Nematode reproduction trend was not different on the susceptible varieties Del 939 and the resistant varieties Emma at these two inoculation dates.

Infection by root-knot nematodes $M$. incognita begins with penetration of the roots by the $\mathrm{J} 2$ at the zone of elongation. In small pot tests, root growth is limited at later plant growth stages, which may reduce availability of suitable penetration sites. Results showed that later inoculation (40 days after planting) resulted in fewer galls and less egg production on sugar beet plants, especially on the susceptible varieties. This reduced the ability and chances to separate susceptible and moderately resistant varieties.

Table (8): Effect of inoculated plant ages (DAP) on reproduction of $M$. incognita as eggs/g root for four sugar beet varieties.

\begin{tabular}{|l|c|c|c|c|c|c|}
\hline \multirow{2}{*}{ Varieties } & \multicolumn{5}{|c|}{ Plant age } & \multirow{2}{*}{ Average } \\
\cline { 2 - 7 } & 0 DAP & 10 DAP & 20 DAP & 30 DAP & 40 DAP & \\
\hline Del 939 & $4325.0 \mathrm{ak}$ & $3721.0 \mathrm{ak}$ & $3199.0 \mathrm{ak}$ & $2954.0 \mathrm{ak}$ & $2127.0 \mathrm{ak}$ & $\mathbf{3 2 6 5 . 2} \mathrm{k}$ \\
\hline Elan & $5101.0 \mathrm{al}$ & $3113.0 \mathrm{al}$ & $2854.0 \mathrm{al}$ & $2878.0 \mathrm{bl}$ & $2491.0 \mathrm{cl}$ & $\mathbf{2 8 8 7 . 4}$ \\
\hline Av poly & $1330.0 \mathrm{am}$ & $1545.0 \mathrm{am}$ & $1661.0 \mathrm{am}$ & $1741.0 \mathrm{bm}$ & $1011.0 \mathrm{~cm}$ & $\mathbf{1 4 5 7 . 6} \mathrm{m}$ \\
\hline Lados & $1421.0 \mathrm{an}$ & $1550.0 \mathrm{an}$ & $1754.0 \mathrm{an}$ & $2013.0 \mathrm{bn}$ & $1691.0 \mathrm{ch}$ & $\mathbf{1 6 8 5 . 8} \mathrm{n}$ \\
\hline M 9680 & $1511.0 \mathrm{an}$ & $1630.0 \mathrm{an}$ & $1524.0 \mathrm{an}$ & $1689.0 \mathrm{bn}$ & $1523.0 \mathrm{cn}$ & $\mathbf{1 5 7 5 . 4} \mathrm{n}$ \\
\hline Emma & $199.0 \mathrm{ao}$ & $387.0 \mathrm{ao}$ & $453.0 \mathrm{ao}$ & $185.0 \mathrm{bo}$ & $134.0 \mathrm{co}$ & $\mathbf{2 7 1 . 6} \mathrm{o}$ \\
\hline Average & $\mathbf{2 3 1 4 . 5} \mathrm{a}$ & $\mathbf{1 9 9 1 . 0} \mathrm{a}$ & $\mathbf{1 9 0 7 . 5} \mathrm{a}$ & $\mathbf{1 7 4 3 . 3} \mathrm{b}$ & $\mathbf{1 3 2 9 . 5} \mathrm{c}$ & $\mathbf{1 8 5 7 . 2}$ \\
\hline
\end{tabular}

Inoculation level was 8000 eggs/ plant.

Results of eggs/g root are the means of 12 replications (six replications/ trial).

Values in each column followed by the same letter (a-f) and values in each row followed by the same letter $(\mathrm{k}-\mathrm{m})$ do not differ significantly $(P>0.001)$ by Duncan least significant difference (LSD) test.

\section{CONCLUSION}

It can be concluded that a gall index based on number of galls with root system was a reliable indicator of the level of resistance on early harvest dates (as early as two weeks) after inoculation with 6000 or more eggs/ plant during 10 to 30 days after planting. If the nematode population is the limiting factor, as few as 500 or 1000 eggs/ plant could be used to separate the different levels of resistance on late harvest dates (8 WAI) either based on the gall index or eggs per gram root. This is important because we have identified a rapid method for assessing resistance in sugar beet genotypes. The selected genotypes could then be assessed for eggs per gram root at 
eight weeks after inoculation with 6000 eggs/plant to verify the resistance level based on egg production.

\section{REFERENCES}

Abd-El-Massih, M.I.; S. El-Eraki and A.Y. El-Gindi (1986). Plant parasitic nematodes associated with sugar beet in Egypt. Bull. Fac. Agric., Cairo Univ., 37: 477-483.

Abdel-Momen, S. M., C. E. Simpson and J. L. Starr (1998). Resistance of interspecific Arachis breeding lines to Meloidogyne javanica and an undecided Meloidogyne species. J. Nematol. 30: 341-346.

Choi, K.; M. D. Burow; G. Church; G. Burow; A.H. Paterson; C.E. Simpson and J. L. Starr (1999). Genetics and mechanism of resistance to Meloidogyne arenaria in peanut germplasm. J. Nemat. 31:283-290.

Culbreath, A.K., N.A Minton; and T.B. Brenneman (1992). Response of Florunner and Southern Runner sugar beet cultivars of chemical management of late leaf spot, southern stem rot, and nematodes. PI. Dis. 76:1199-1203.

Dickson, D.W., and T.E. Hewlett (1989). Effect of bahiagrass and nematicides on Meloidogyne arenaria on sugar beet. J. Nematol. 21:671-676.

Diez, J.A., and D.B. Dusenbery (1989). Preferred temperature of Meloidogyne incognita. J. Nematol. 21: pp. 99-104.

Duncan, D. B. (1955). Multiple range and multiple $F$ tests. Biometrics 11:1-42,

El-Eraki, S.; M.I. Abd-El-Massih and A.Y. El-Ginai (1986). Resistant reaction of some sugar beet cultivars to infection with Meloidogyne javanica and Meloidogyne incognita. Bull. Fac. Agric., Ain- Shams Univ., 37: 10371044.

El-Nagdi, W.M.A.; M.M.A. Youssef and Z.R. Moustafa (2004). Reaction of sugar beet varieties to Meloidogyne incognita root knot nematode based on quantitative and qualitative yield characteristics. Pak. J. Nematol., 22:157-165.

El-Sherif, A.G.; A.R. Refaei, M.E. El-Nagar and Hagar, M. M. Salem (2007). The role of eggs inoculum level of Meloidogyne incognita on their reproduction and host reaction. Afri. J. Agric. Res. 2(4), pp. 159-163.

Gohar, I.M.A. and M.F. Maareg (2005). Relationship Between Crop Losses and Initial Population Densities of Root-knot Nematode, Meloidogyne incognita in soil of Sugarbeet Grown in West Nubariya District. Egypt. J. Agric. Res., 83 (4): $1315-1328$.

Harris, D. K.; H. R. Boerma; R. S. Hussey and S. L. Finnerty (2003). Additional sources of soybean germplasm resistant to two species of root-knot nematode. Crop Sci. 43:1848-1851.

Holbrook, C.C.; D.A., Knauft and D.W. Dickson (1983). A technique for screening sugar beet for resistance to Meloidogyne arenaria. Plant Disease 67:957-958. 
Hussey, R.S. and K.R. Barker (1973). A comparison of methods of collecting inocula of Meloidogyne spp., including a new technique. Plant Disease Reporter 57:1025-1028.

Hussey, R.S., and G.J.W. Janssen (2002). Root-knot nematode: Meloidogyne species. Pp. 43-70 in J. L. Starr, R. Cook, and J. Bridge, eds. Plant Resistance to Parasitic Nematodes. Wallingford, UK: CAB International.

Ibrahim, I.K.A. (1982). Species and races of root- knot nematodes and their relationship to economic host plants in northern Egypt. Pages: 66-84. In: Proc. $3^{\text {rd }}$ Res. and Planning Conf. on Root-Knot Nematodes Meloidogyne spp. Coimbra, Portugal.

Ismail, A.E.; H.Z. Aboul-Eid and S.Y. Besheit (1996). Effects of Meloidogyne incognita on growth response and technological characters of certain sugar beet varieties. Afro-Asian J. Nematol., 6 (2): 195- 202.

Koenning, S.R.; C. Overstreet; J.W. Noling; P.A Donald; J. O. Becker and B. A Fortnum (1999). Survey of crop losses in response to phytoparasitic nematodes in the United States for 1994. J. Nematol. 31:587-618.

Luzzi, B.M.; H. R. Boerma; and R. S. Hussey (1987). Resistance to three species of root-knot nematode in soybean. Crop Sci. 27: 258-262.

Maareg, M.F.; I.M.A. Gohar and A.M. Abdel Aal (2005). Susceptibility of twenty sugarbeet varieties to the root-knot nematode, Meloidogyne incognita at West Nubariya District. Egypt. G. Agric. Res., 83 (2): 789 801.

Maareg, M.F.; M.A Hassanein; A.I. Allam and B.A. Oteifa, (1998). Susceptibility of twenty-six sugar beet varieties to root-knot nematodes, Meloidogyne spp. in the newly reclaimed sandy soils of Al-Bostan region. Egypt. J. Agronematol., 2(1): 11-125.

Noe, J.P. (1991). Development of Meloidogyne arenaria on peanut and soybean under two temperature cycles. J. Nematol. 23: 468-476.

Oteifa, B.A. and D.M. El-Gindi, (1982). Relative susceptibility of certain commercially important cultivars to existing biotypes of Meloidogyne incognita and Meloidogyne javanica in Nile-Delta, Egypt. Pages: 157169. In: Proc. $3^{\text {rd }}$ Res. and Planning Conf. on Root-Knot Nematodes Meloidogyne spp. Coimbra, Portugal.

Roberts, P.A. (2002). Concepts and consequences of resistance. Pp. 23-41 in J. L. Starr, R. Cook, and J. Bridge, eds. Plant Resistance to Parasitic Nematodes. Wallingford, UK: CAB International.

Sasser, J.N. (1980). Root knot nematodes: A global menace to crop production. PI. Dis. 64:36-41.

Sasser, J.N., and D.W. Freckman (1987). A world perspective on Nematology: The role of the society. Pp. 7-14 in J. A. Veech, D. W.Dickson, eds. Vistas on Nematology. Hyattsville, MD: U.S.A Society of Nematology, Inc.

Sasser, J.N.; C.C Carter and K.M. Hartman (1984). Standardization of Host Suitability Studies and Reporting of Resistance to root-knot Nematodes. North Carolina State University, Raleigh and United States Agency for International Development. 
Taylor, A.L. and J.N. Sasser (1978). Biology, identification and control of rootknot nematodes (Meloidogyne species). N.C. State University Graphics: Raleigh, N.C.

Vovlas, N.; H.F. Rapoport; R.M. Jimenez-Diaz and P. Castillo (2005). Differences in feeding sites induced by root-knot nematodes, Meloidogyne spp., in chickpea. Phytopathol. 95:368-375.

Weiland, J.J. and M.H. Yu (2003). A Cleaved Amplified Polymorphic Sequence (CAPS) Marker Associated with Root-Knot Nematode Resistance in Sugar beet. Crop Sci. 43:1814-1818.

Yu, M.H. (1995). Identification of a Beta maritima source of resistance to rootknot nematode for sugar beet. Crop Sci. 35:1288-1290.

Yu, M.H. (1995). Root-knot nematode development and root gall formation in sugar beet. J. sugar beet res. 32, $\mathrm{n}^{01}$, pp. 47-58.

Yu, M.H. (2003). Development of root-knot nematode- resistant sugar beet. Poster presentation. $1^{\text {st }}$ joint IIRB-ASSBT Congress, 26"'Feb.-1 March 2003, San Antonio (USA).

Yu, M.H.; L.M Pakish and H. Zhou (2001). An isozyme marker for resistance to root-knot nematode in sugar beet. Crop Sc., 41, 1051-1 053.

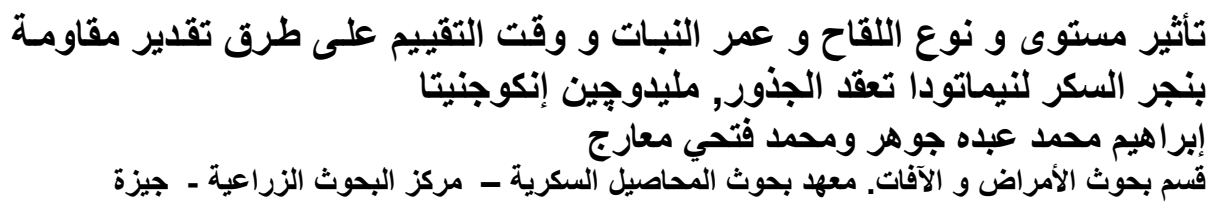

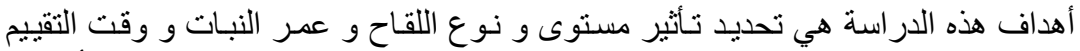

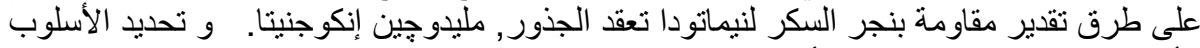

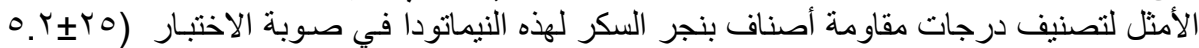

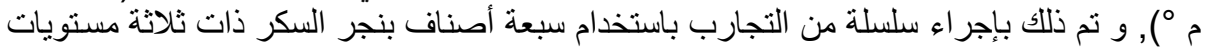

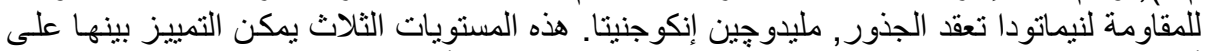

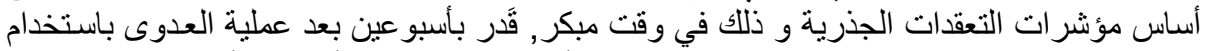

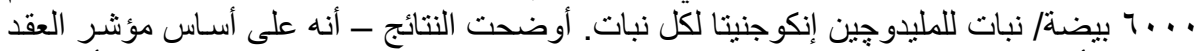

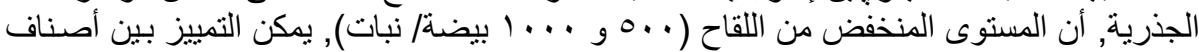

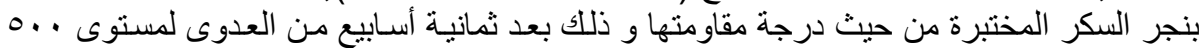

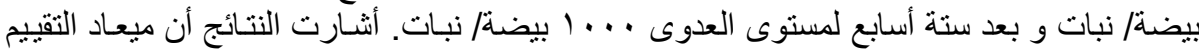

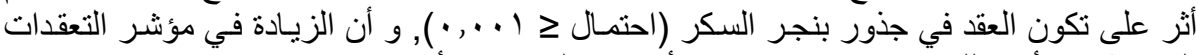
الجذرية كان أكبر للصنف إيلان عن باقي الأصناف المنئ المختبرة الأخرى.

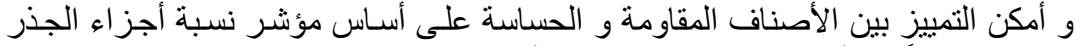

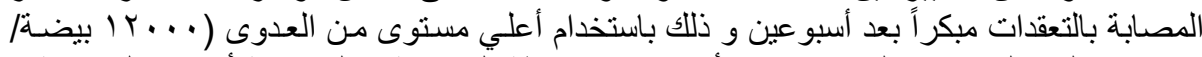

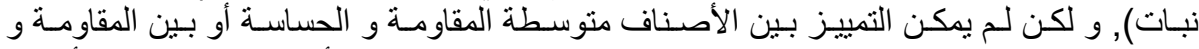

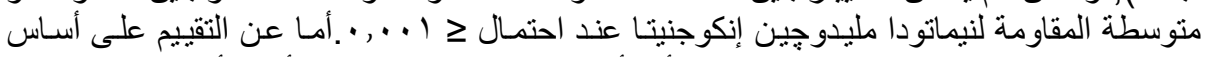

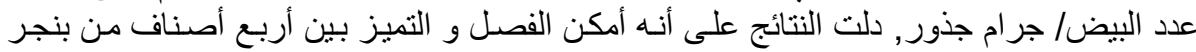

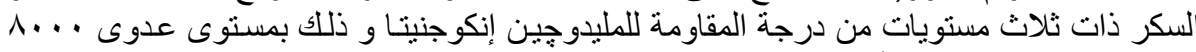

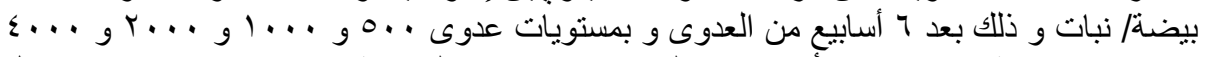

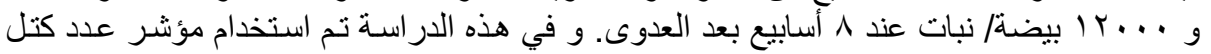


البيض و كتل البيض بالإضافة إلى المقاييس الأخرى, عدد العقد الجذرية و مؤشر التعقدات الجذريـة

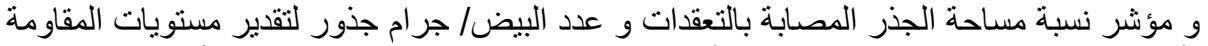

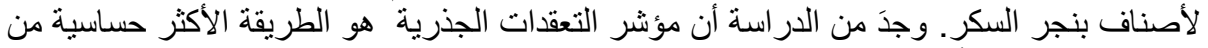

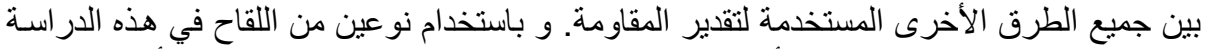

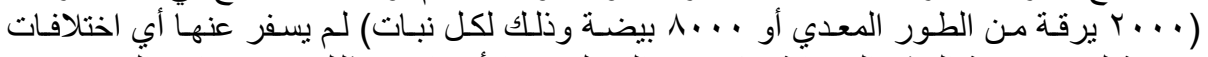

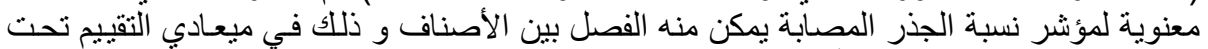

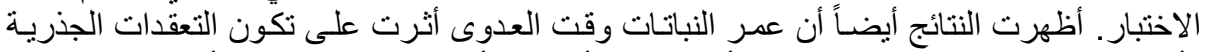

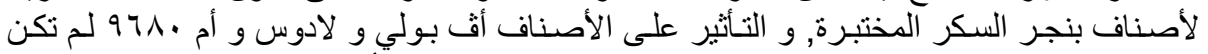

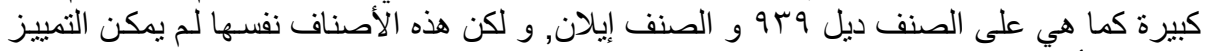

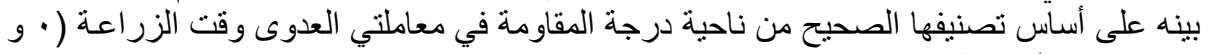

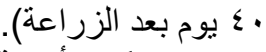
تكمن أهميـة هذه الدر اسـة في تحديد طريقة سـريعة للتقييم مقاومـة أصناف بنجر السكر

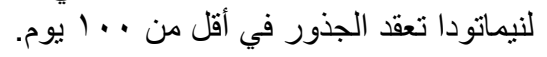

